\title{
IPSO Algorithm for Maximization of System Loadability, Voltage Stability and Loss Minimisation by Optimal DG Placement
}

\author{
N. Prema Kumar ${ }^{1}$, K. Mercy Rosalina ${ }^{2}$ \\ Associate Professor, Department of Electrical Engineering, Andhra University ${ }^{1}$ \\ Research Scholar, Department of Electrical Engineering, Andhra University, Visakhapatnam ${ }^{2}$
}

\begin{abstract}
Under constantly increased electricity demands and power transactions, it is becoming more essential to enhance the system loadability of existing distribution networks such that more power transfers can be accommodated with less network expansion cost. Instead of building new distribution substations or lines, proper installation of distribution generation units can make the distribution networks accommodate more power transfers with less expansion cost. In this paper, the problem to maximize power system loadability by optimally installing DG units is formulated as an optimization problem. To reduce the complexity of the problem, the locations suitable for DG installations are first investigated with multi objective optimisation based on inertia weighted particle swam optimisation (IPSO) method with power loss index (PLI) and voltage stability index (VSI). The size of the DG is to be installed is determined from the standard analytical methods. The proposed IPSO algorithms is tested on two standard test systems, i.e. 33-, and 69- bus radial distribution systems. The proposed algorithms has been implemented using MATLAB R2010a running on Intel Core 2 Duo processor $2.93 \mathrm{GHz}, 1.96 \mathrm{~GB}$ of RAM. All evaluations were carried out with self developed MATLAB codes.
\end{abstract}

Keywords: Distributed generation, Power loss index (PLI), Voltage stability index (VSI), System loadability, IPSO.

\section{INTRODUCTION}

It is expectable that the future economic developments will result in large electric demands regionally and, in the deregulated power systems, due to open access to the transmission networks a great numbers of various power transactions will incur huge changing power flows, stability and loadability of the system. In this view, serious threats to power system security might occur. Distribution generation can be used to balance the distribution line flows and system voltage, leading to lower system losses, higher loadability and improved voltage regulation. Most of the studies on optimal DG installations are oriented to technical, economic or both concerns.

The problem of the voltage stability has risen since the beginning due to large difference in generation and load demands, and to the limited expansion because of high investment cost of equipments, of distribution systems. In order to meet the load demand distribution company usually integrate the distributed resources to the existing system. Distributed resources are the power sources (active or reactive) that can be connected to a distribution system by a distribution company or by the customer at the customer side of the meter [1]. The distributed resources, if strategically located and operated, defer or eliminate system upgrades by improving various energy efficiency defining parameters like voltage profile, power losses and loadability limit. However, for better energy performance the simultaneous improvement in these parameters is required. Here, voltage stability is the major concern as it improves the reliability of supplying power to the consumers.

The improvement in system performance by network reconfiguration is limited to the load balancing, as the resultant power flow remains the same [8]. Therefore, in order to meet the growing load demand the power utilities integrate the distributed resources with the existing system. However, this is a big challenge to find the optimal size and location of these resources as the load varies with time, weather condition and the state of economy. There exists an extensive effort to find the optimal placement of distributed resources in [2]-[13].

The effect of load behavior using the different load models has been presented in [9] and [10] while finding the optimal size and location of the distributed resources using multi-objective approach. On the other hand, in [11] the size of the distributed resource for voltage support is obtained under particular loading conditions. The effect of capacitor placement while finding the optimal configuration for different loading patterns is presented in [12]. Authors in [13] and [14] achieve the same objective for distributed generator (DG) placement. Also, a voltage quality index is developed, in order to find the optimal location for DG in distribution system. Using the recursive load flow equations, paper [15] presents the expression for the calculation of the size of DG and optimizes the system operation for maximum loss reduction with single and multi placement of DG. From the literature, it can be observed that the different approach uses voltage profile as main objective in order to improve the system performance. However, the improvement in voltage profile does not guarantee that the system can serve more loads at the respective node. Therefore, in order to improve the reliability of supplying power the distribution company need to enhance the voltage stability rather 
considering the node voltage profile, as the distribution system usually operate on the verge of its loadability limit.

\section{PROBLEM FORMATION}

The problem is to determine optimal location and size of DG units which minimizes the total real power losses and to improve the voltage profile, stability and lodability of the system under different system operating constraints. The operating constraints are voltage profile of the system, radial structure of the distribution system, real and reactive power generation limits and power balance constraint.

$$
L F_{i+1}=\frac{-\left(r_{i} P_{i}+x_{i} Q_{i}\right)+\sqrt{\left(r_{i}^{2}+x_{i}^{2}\right)\left(P_{i}^{2}+Q_{i}^{2}\right)}}{2\left(x_{i} P_{i}-r_{i} Q_{i}\right)^{2}} V_{i}^{2}
$$

Here, $\mathrm{LFi}+1$ is the loadability factor at node ' $\mathrm{i}+1$ ' which when multiply with the existing load demand (in kVA) at respective node defines its loadability, i.e. the load that can be connected before voltage collapses at respective node. Equation (1) also represents that the loadability factor depends upon the load demands therefore; it can vary significantly with the placement of distributed resources as they alter load demand at respective node. However, the placement of these resources at a particular node doesn't guarantee for simultaneous improvement in any other energy efficiency defining parameters. This paper finds the location and size of distributed resources for improvement of voltage stability, in order to serve as maximum as possible number of consumers at a node having worst level of loadability limit, in the system configuration. In order to evaluate the loss reduction, improved voltage regulation and system voltage stability, power utilities need to know the possible load that can be connected at a respective node. This can be easily defined by knowing the loadability factor at the respective node, as described in [2]. Formation of the multi-objective function is as follows:

Objective-I

The objective function of the problem is formulated to maximize the lodability of the sytem by improving the loading factor which is a function of the voltage profile of radial distribution system, which is given by

$$
\text { Maximize } \mathrm{f}=\max \left(\mathrm{V}_{\mathrm{i}}\right)
$$

The above expression can also be written as minimization voltage deviation index in the radial distribution system, which is given by

$$
\text { Minimize } \mathrm{f}=\min \left(\operatorname{abs}\left(\sum_{\mathrm{i}=2}^{\mathrm{n}} \text { VDI }\right)\right)
$$

Where, $\mathrm{n}$ is number of buses in the radial distribution system and VDI is called voltage deviation index is expressed as follows

$$
\text { VDI }=\operatorname{abs}\left(\sum_{i=2}^{n} \frac{\left(V_{\text {ref }}-V_{i}\right)}{V_{\text {ref }}}\right)
$$

Where, Vref is reference voltage of the ith bus usually it is taken as Vref $=1.0$ p.u. and Vi is the voltage magnitude of ith bus after DG unit placement.

Objective-II

The objective function of the problem is formulated to maximize the realpower loss reduction in radial distribution system, which is given by

$$
\text { Maximize } \mathrm{f}=\max \left(\Delta \mathrm{P}_{\mathrm{Loss}}^{\mathrm{DG}}\right)
$$

The expression can also be written as minimization power loss in the radial distribution system, which is given by inimize

$$
\mathrm{f}=\min \left(\sum_{\mathrm{i}=1}^{\mathrm{n}-1} \mathrm{P}_{\text {Loss }}(\mathrm{i}, \mathrm{i}+1)\right)
$$

Where, $\mathrm{n}$ is number of buses in the radial distribution system or this can also expressed as follows

$$
\begin{aligned}
& \text { Minimize } f=\min (\mathrm{PLI}) \\
& \mathrm{PLI}=\frac{\mathrm{P}_{\text {LWDG }}}{\mathrm{P}_{\text {LWODG }}}
\end{aligned}
$$

Where, PLI is called power loss index, $\mathrm{P}_{\mathrm{LWDG}}$ is power loss with DG and $\mathrm{P}_{\text {Lwodg }}$ is power loss without DG Conversion of multi objective functions into single objective functions

$$
\begin{gathered}
\mathrm{f}_{1}=\min (\mathrm{PLI}) \\
\mathrm{f}_{2}=\min (\mathrm{VDI})
\end{gathered}
$$

$\mathrm{f}_{1}, \mathrm{f}_{2}$ are two different objective functions, using weight factor method multi objective function is expressed as follows

$$
\mathrm{f}_{\mathrm{mo}}=\mathrm{W}_{1} * \mathrm{f}_{1}+\mathrm{W}_{2} * \mathrm{f}_{2}
$$

Where, W1 and $\mathrm{W} 2$ are called weight factors $\mathrm{W} 1=0.8$; $\mathrm{W} 2=0.2$

$$
\text { Minimize } \mathrm{f}=\min \left(\mathrm{f}_{\mathrm{mo}}\right)
$$

Subjected to constraints:

Power balance constraints

$$
\sum \mathrm{P}_{\mathrm{DGi}} \leq \sum \mathrm{P}_{\mathrm{Di}}
$$

Voltage limits

$$
\mathrm{V}_{\min } \leq \mathrm{V}_{\mathrm{i}} \leq \mathrm{V}_{\max }
$$

Vmin and Vmax is minimum and maximum voltage limits of ith bus

Real power generation limits

$$
P_{D G \min } \leq P_{D G i} \leq P_{D G \max }
$$

Reactive power generation limits

$$
Q_{D G \min } \leq Q_{D G i} \leq Q_{D G \max }
$$

A. Solution techniques for placement of distributed resources for improved voltage stability and loadability The computational steps involved in the solution technique for improvement in voltage stability of radial distribution system, based upon the mathematical formulation presented are as follows:

Step1: Run the load flow program by assuming flat voltage profile, and calculate active and reactive load demand at each node.

Step2: Compute the node voltage, loadability factor, power loss and distributed resource size at each node for base case.

Step3: Place a distributed resource, one at a time, as DG of size equal to active component of load demand.

Step4: Run the load flow and re-calculate the node voltage and loadability limit at each node.

Step5: Print the size of the distributed resources for which the system can serve as maximum as possible number of consumers at a node having worst level of loadability limit. Also, print system power loss, minimum node voltage and worst level of loadability limit. 
III.IMPLEMENTATION OF IPSO ALGORITHM TO DG PLACEMENT PROBLEM

This algorithm handles a population of individuals, in parallel, to probe capable areas of a multidimensional space where the optimal solution is searched. The individual are called particles and the population is called swam (solution matrix contains DG sizes and locations). Each particle in swam moves towards the optimal point with adaptive velocity. Each particle in the population is treated as a mass less and volume less point in a ndimensional search space. Mathematically, the position and velocity of the particle, in a n-dimensional vector is represented as:

$$
\begin{aligned}
& \mathrm{Xm}=(\mathrm{xm}, 1, \mathrm{xm}, 2, \mathrm{xm}, 3, \ldots \ldots \ldots . \mathrm{xm}, \mathrm{n}) \\
& \mathrm{Vm}=(\mathrm{vm}, 1, \mathrm{vm}, 2, \mathrm{vm}, 3, \ldots \ldots \ldots . \mathrm{vm}, \mathrm{n})
\end{aligned}
$$

Alternatively, the best position related to the lowest value of the objective function for each particle is:

pbestm = (pbestm, $1, \quad$ pbestm, $2, \quad$ pbestm,3, ...........pbestm,n), and the global best position among all the particles or best pbest is denoted as:

gbestm = $\quad$ gbestm, $1, \quad$ gbestm, $2, \quad$ gbestm, 3 , ..........gbestm,n), during the iteration procedure, the velocity and position of the particles are updated.

It should be noticed that the value of DG size varies between 0 to $70 \%$ of the loads plus losses. A large inertia weight $(w)$ facilitates a global search while a small inertia weight facilitates a local search. This is regarded as the position of a particle during the optimization process. The steps used in proposed algorithm are given below.

\section{A. Steps followed in IPSO algorithm}

Step 1: Read the input system data and initialize population, number of particles, limits of DG size, voltage limits, parameters of algorithm etc.

Step 2: Calculation of objective function by using Forward-Backward sweep based distribution load flow.

Step 3: Calculate pbest i.e. objective function value of each particle in the population of the current iteration is compared with its previous iteration and the position of the particle having a lower objective function value as pbest for the current iteration is recorded:

$$
\text { pbest }_{m}^{k+1}= \begin{cases}\text { pbest }_{m}^{k} & \text { if } f_{m}^{k+1} \geq f_{m}^{k} \\ x_{m}^{k+1} & \text { if } f_{m}^{k+1} \leq f_{m}^{k}\end{cases}
$$

Where, $\mathrm{k}$ is the number of iterations, and $\mathrm{f}$ is objective function evaluated for the particle.

Step 4: Calculation of gbest i.e. the best objective function associated with the pbest among all particles in the current iteration is compared with that in the previous iteration and the lower value is selected as the current overall gbest.

$$
\text { gbest }_{m}^{k+1}= \begin{cases}\text { gbest }_{\mathrm{m}}^{\mathrm{k}} & \text { if } \mathrm{f}_{\mathrm{m}}^{\mathrm{k}+1} \geq \mathrm{f}_{\mathrm{m}}^{\mathrm{k}} \\ \text { pbest }_{\mathrm{m}}^{\mathrm{k}+1} & \text { if } \mathrm{f}_{\mathrm{m}}^{\mathrm{k}+1} \leq \mathrm{f}_{\mathrm{m}}^{\mathrm{k}}\end{cases}
$$

Step 5: Velocity updating, after calculation of the pbest and gbest the velocity of particles for the next iteration should be modified by using equation:

$$
\begin{aligned}
& V_{m}^{k+1}+\omega V_{m}^{k}+C_{1} \operatorname{rand}\left(\text { pbest }_{m}^{k}-X_{m}^{k}\right)+ \\
& C_{2} \operatorname{rand}\left(\text { gbest }^{k}-X_{m}^{k}\right)
\end{aligned}
$$

Where, the parameters of the above equation should be determined in advance and $\omega$ is the inertia weight factor, defined as follows:

$$
\omega=\omega_{\max }-\frac{\left(\omega_{\max }-\omega_{\min }\right)}{\text { iter }_{\max }} * \text { iter }
$$

$\mathrm{C} 1, \mathrm{C} 2$ are the acceleration coefficients usually in range $[1,2]$. A large inertia weight $(w)$ facilitates a global search while a small inertia weight facilitates a local search.

Step 6: Check the velocity components constraints occurring in the limits from the following conditions,

If Vid $>$ Vmax, then Vid = Vmax (or) If Vid $<-$ Vmax then

$$
\mathrm{Vid}=-\mathrm{V} \max
$$

Step 7: Position updating, the position of each particle at the next iteration $(\mathrm{k}+1)$ is modified as follows:

$$
X_{j}^{k+1}=X_{j}^{k}+V_{j}^{k+1}
$$

Step 8: If the number of iterations reaches the maximum i.e. iter = itermax, then go to step 9. Otherwise, go to step 2 .

Step 9: The individual that generates the latest gbest is the optimal locations and sizes of DGs with minimum power loss.

B. Description of parameters for ipso algorithm

Algorithm parameter selection plays major role for any optimization algorithms in terms of performance. Hence, parameter tuning is required for optimization techniques. The values assigned for these parameters are selected by the number of trails on the performance of the proposed method. The parameter description and assigned values for IPSO are furnished in the Table 1.

TABLE I Parameter description for IPSO algorithm

\begin{tabular}{|l|l|l|l|}
\hline Type & Parameter & Description & $\begin{array}{l}\text { Assigned } \\
\text { value }\end{array}$ \\
\hline \multirow{4}{*}{ IPSO } & $\mathrm{P}$ & Population size & 150 \\
\cline { 2 - 4 } & Wmax & $\begin{array}{l}\text { Maximum inertia } \\
\text { weight factor }\end{array}$ & 0.9 \\
\cline { 2 - 4 } & Wmin & $\begin{array}{l}\text { Minimum inertia } \\
\text { weight factor }\end{array}$ & 0.4 \\
\cline { 2 - 4 } & $\mathrm{C} 1, \mathrm{C} 2$ & $\begin{array}{l}\text { Cognitive } \\
\text { parameters }\end{array}$ & 2,2 \\
\cline { 2 - 4 } & Iter max & $\begin{array}{l}\text { Maximum no of } \\
\text { iterations }\end{array}$ & 150 \\
\hline
\end{tabular}

\section{IV.SIMULATION RESULTS AND DISCUSSIONS}

The proposed IPSO algorithms is tested on two standard test systems, i.e. 33-, and 69- bus radial distribution systems. The proposed algorithms has been implemented using MATLAB R2010a running on Intel Core 2 Duo processor $2.93 \mathrm{GHz}, 1.96 \mathrm{~GB}$ of RAM. All evaluations were carried out with self developed MATLAB codes. The optimal parameters setting for the proposed algorithm are given in Table 1 for all systems. It is assumed that Maximum DG size is considered in the range of $0-70 \%$ of the total real power load and the maximum number of DGs that are to be connected is restricted to three for 33bus and 69-bus systems in this study. It is also assumed that all loads are constant power loads and the system load curve is fixed (peak load). In this study, DGs are modelled as Type-1 $(p . f=1)$ DGs. 
The 33-bus radial distribution system consists of 33 buses The 69-bus radial distribution system have 69 buses and and 32 branches; total load of 3.72 MW, 2.3 Mvar and the 68 branches, total load of 3.80 MW, 2.69 Mvar and the real and reactive power losses in the system is $210.78 \mathrm{~kW}$ and 143 kvar.

real and reactive power losses in the system is $224.7 \mathrm{~kW}$ and 102.13 kvar.
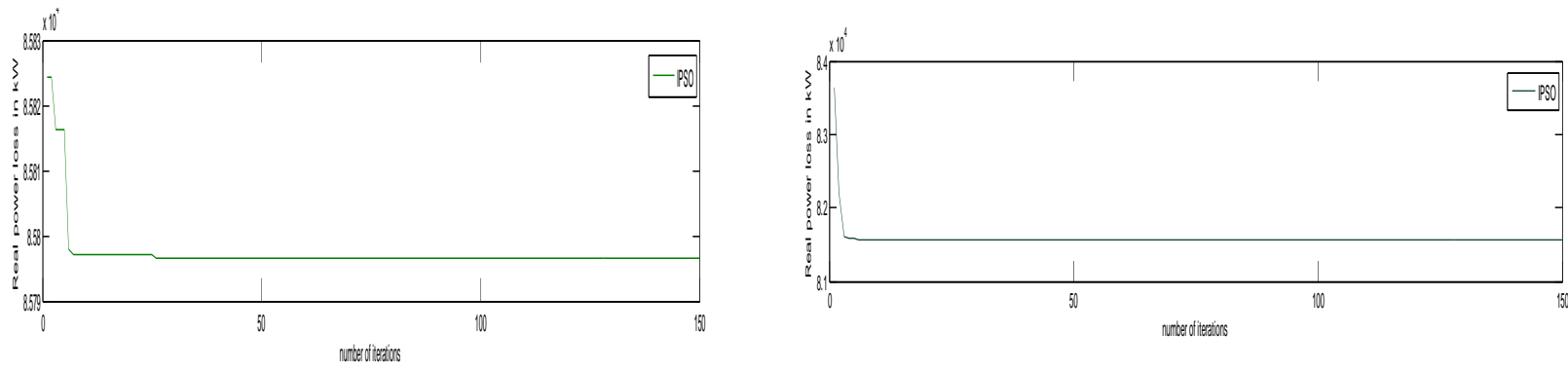

Fig.1 Convergence characteristics for 33-bus RDS

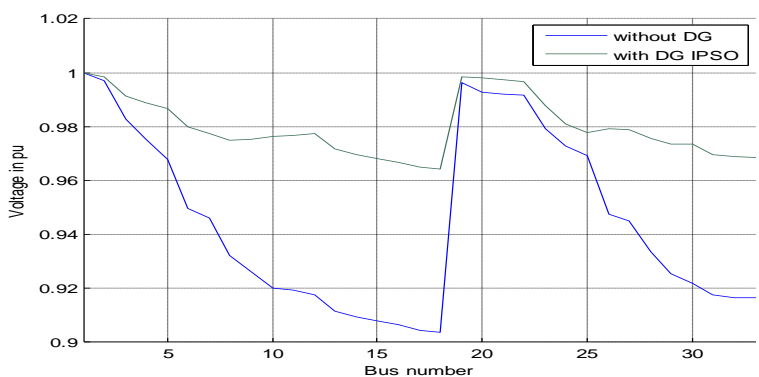

Fig. 2 Voltage profile correction for 33-bus RDS
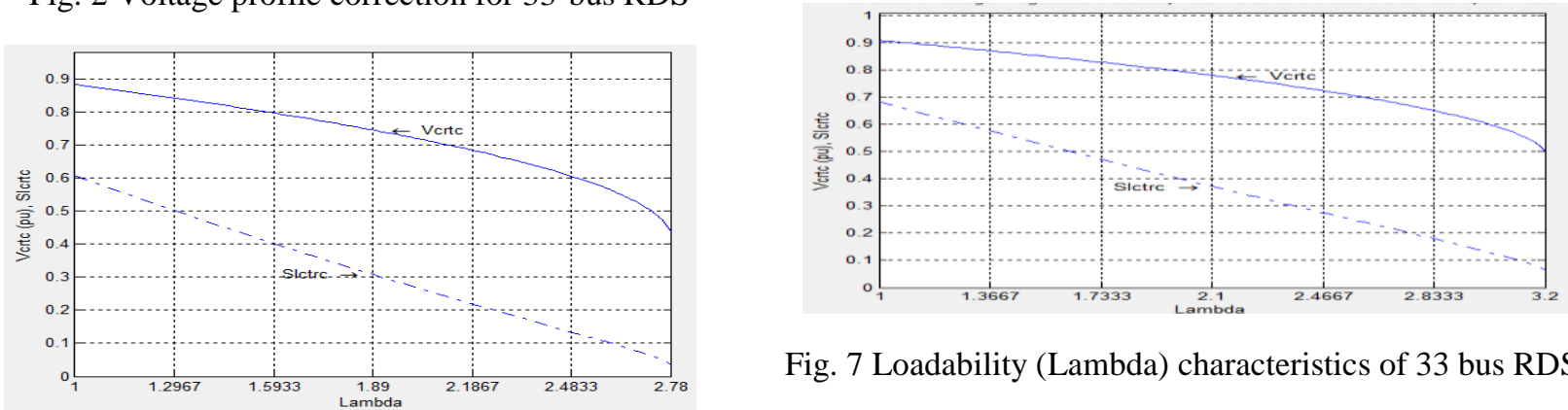

Fig. 7 Loadability (Lambda) characteristics of 33 bus RDS

Fig. 3 Loadability (Lambda) characteristics of 33 bus RDS

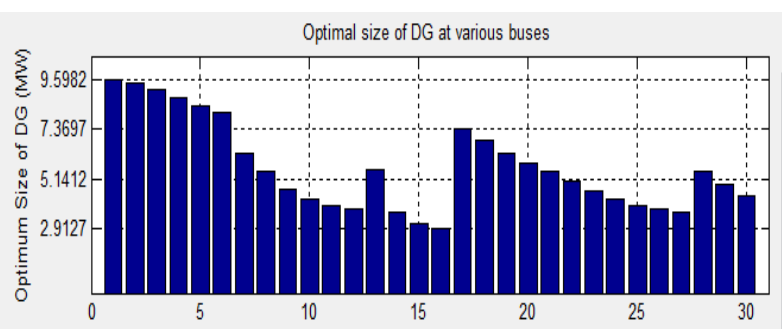

Fig. 4 Optimal size of DG at all busses in 33 bus system

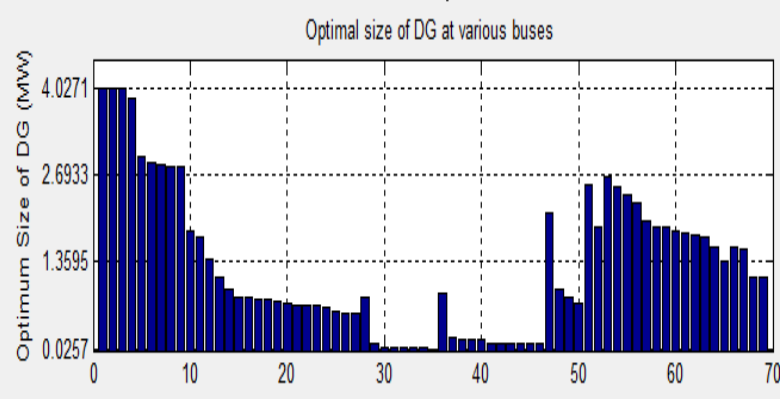

Fig. 8 Optimal size of DG at all busses in 69 bus system

TABLE II Numerical results of proposed algorithms for 33- and 69-bus system

\begin{tabular}{|c|c|c|c|c|c|c|c|c|c|c|}
\hline \multirow{2}{*}{$\begin{array}{l}\text { Type } \\
\text { of } \\
\text { RDS }\end{array}$} & \multicolumn{2}{|c|}{ P Loss(MW) } & \multirow[b]{2}{*}{$\begin{array}{l}\% \text { Loss } \\
\text { reduction }\end{array}$} & \multirow[b]{2}{*}{$\begin{array}{l}\text { Optimal } \\
\text { Bus No. }\end{array}$} & \multirow{2}{*}{$\begin{array}{l}\text { DG size } \\
\text { PDG } \\
(\mathrm{MW})\end{array}$} & \multirow[b]{2}{*}{ SI } & \multirow[b]{2}{*}{$\begin{array}{l}\text { Loading } \\
\text { Factor }\end{array}$} & \multirow{2}{*}{$\begin{array}{l}\text { Max. } \\
\text { Load } \\
\text { ability }\end{array}$} & \multirow[b]{2}{*}{ VPI } & \multirow{2}{*}{$\begin{array}{l}\text { CPU } \\
\text { time } \\
(s)\end{array}$} \\
\hline & $\begin{array}{l}\text { Before } \\
\text { DGs }\end{array}$ & $\begin{array}{l}\text { After } \\
\text { DG }\end{array}$ & & & & & & & & \\
\hline \multirow{3}{*}{$\begin{array}{l}33 \\
\text { Bus }\end{array}$} & \multirow{3}{*}{0.21078} & \multirow{3}{*}{$\begin{array}{l}0.08 \\
579\end{array}$} & \multirow{3}{*}{59.29} & 20 & 0.3599 & \multirow{3}{*}{0.6065} & \multirow{3}{*}{2.05848} & \multirow{3}{*}{5.04} & \multirow{3}{*}{0.0643} & \multirow{3}{*}{8.65} \\
\hline & & & & 30 & 1.1088 & & & & & \\
\hline & & & & 12 & 0.9543 & & & & & \\
\hline \multirow{3}{*}{$\begin{array}{l}66 \\
\text { Bus }\end{array}$} & \multirow{3}{*}{0.2247} & \multirow{3}{*}{$\begin{array}{l}0.08 \\
155\end{array}$} & \multirow{3}{*}{63.7} & 20 & 0.4724 & \multirow{3}{*}{0.6833} & \multirow{3}{*}{2.329} & \multirow{3}{*}{4.1} & \multirow{3}{*}{0.0973} & \multirow{3}{*}{13.64} \\
\hline & & & & 52 & 0.5670 & & & & & \\
\hline & & & & 64 & 1.5014 & & & & & \\
\hline
\end{tabular}


The effect of optimal access point and capacity of Type-1 DGs on the real power loss of the system, percentage loss reduction, various performance indices, lodability and computation time are given in Table 2 . It is evident that the reduction in line current could reduce the line losses in turn reduces line voltage drop and improves the overall voltage profile. The effect of inserting DGs on the voltage profile of the system, loadability and DG sizes are shown in Figures 1 to 8, improvement in system performance parameters under Type-1 DGs is very significant.

\section{CONCLUSION}

In this paper, an efficient DG installation strategy is proposed to enhance the system loadability such that the existing transmission networks can accommodate more power transfers. The application of IPSO algorithm has been proposed to solve optimal location and size of DGs radial distribution systems for minimum real power loss and improved system lodability excluding load models. The effectiveness of the proposed algorithms has been investigated on radial power distribution systems having 33- and 69-buses. From the numerical results of the two test systems has shown that, proposed algorithm is succeeded in achieving the goal of real power loss minimization and loadbility. The efficiency of the proposed method is validated with the test results of the DG installation scheme suggested for transmission system loadability enhancement properly consistent with specific technical concerns

\section{REFERENCES}

[1] E G Carrano, et.al.,, "Electric Distribution Network Multi objective Design using a Problem-Specific Genetic Algorithm", IEEE Transactions on Power Delivery, Volume 21, Number 2, 2006, pp.214-220.

[2] M H Nehrir and C Wang, "Analytical Approaches for Optimal Placement of Distributed Generation sources in Power Systems", IEEE Transactions on Power Systems, Volume 19, Number 4, 2004, pp. 712-718.

[3] G. W. Chang, Senior Member, IEEE, S. Y. Chu, Student Member, IEEE, and H. L. Wang, Student Member, IEEE, "An Improved Backward/Forward Sweep Load Flow Algorithm for Radial Distribution Systems," IEEE Transactions on Power Systems, vol. 22, no. 2, may 2007, pp.882-884

[4] Pavlos S. Georgilakis, Senior Member, IEEE, and Nikos D. Hatziargyriou, Fellow, IEEE, "Optimal Distributed Generation Placement in Power Distribution Networks: Models, Methods, and Future Research," IEEE Transaction on Power Systems, December 24, 2012, p.p. 01051-2012.

[5] T. N. Shukla, S.P. Singh, K. B. Naik, "Allocation of optimal distributed generation using Genetic Algorithm for minimum system losses in radial distribution networks," International Journal of Engineering, Science and Technology Vol. 2, No. 3, 2010, pp. 94-106.

[6] T. Xiao-bo, W. Xue-hong, "A New Method of Distributed Generation Optimal Placement Based on Load Centroid," IEEE Asia-Pacific Power and Energy Engineering Conference (APPEEC), 2011, pp.1-5.

[7] Dr. Ganga Agnihotri, Jitendra Singh Bhadoriya, "Optimal Placement and Sizing of Multi-Distributed Generation (DG) Including Different Load Models using Particle Swarm Optimization (PSO)"

[8] S. Kumar Injeti, Dr. Navuri P Kumar, "Optimal Planning of Distributed Generation for Improved Voltage Stability and Loss Reduction," International Journal of Computer Applications (0975 - 8887) Volume 15- No.1, February 2011, pp. 41-46.
9] D. Singh, D. Singh, and R.K. Misra. "Effect of Load Models in Distributed Generation Planning" IEEE Transactions on Power Systems, vol. 22, no. 4 pp. $2204-2212$, Nov. 2007.

[10] D. Singh, D. Singh, and K. S. Verma, "Multiobjective Optimization for DG Planning With Load Models", IEEE Trans. on Power Systems, Vol. 24, no. 1,pp. 227-236, Feb. 2009.

[11] K. Zou, A.P. Agalgaonkar, K.M. Muttaqi, and S. Perera, "Voltage support by distributed generation units and shunt capacitors in distributed system" IEEE Power \& Energy Society General Meeting. pp. 1-8. 2009

[12] D Singh, et.al., "GA based Optimal Sizing \& Placement of Distributed Generation for Loss Minimization," In Proc. of Word Academy of Science, Engineering and Technology, Volume. 26, 2007, pp. 381-387.

[13] D Singh, et.al., "Multi-objective Optimization for DG Planning With Load Models," IEEE Transactions on Power Systems, Volume 24, Number 1, 2009, pp. 427-436.

[14] M Gandomkar, et.al. "A Genetic-Based Tabu Search Algorithm for Optimal DG Allocation in Distribution Networks," Elect. Power Comp. and Syst., Volume 33, 2005, pp. 1351-1362.

15] D Singh, et.al., "Effect of Load Models in Distributed Generation Planning," IEEE Transactions on Power Systems, Volume 22, Number 4, 2007, pp. 2204-2212.

[16] N Acharya, et.al. "An analytical approach for DG allocation in primary distribution network," Int. J. of Elect. Power and Ener. Syst. Volume 28, 2006, pp. 669-678.

17] V. Farahani, B. Vahidi, and H. A. Abyaneh, "Reconfiguration and capacitor placement simultaneously for energy loss reduction based on an improved reconfiguration method," IEEE Trans. Power Systems, vol. 27, no. 2, pp. 587-595, May 2012

18] V. F. Martins and C. L. T. Borges, "Active Distribution Network Integrated Planning Incorporating Distributed Generation and Load Response Uncertainties," IEEE Trans. Power Systems, vol. 26, no. 4, pp. 2164-2172, Nov.2011.

\section{BIOGRAPHIES}

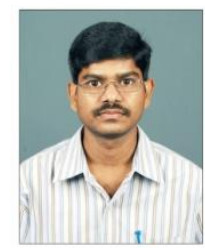

Dr. N. Prema Kumar is working with department of Electrical Engineering, Andhra University as Associate Professor. His current research interests include Power systems, Electrical drives, high voltage engineering and signal processing techniques.

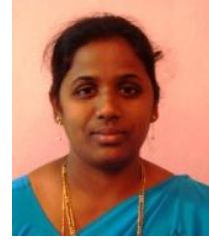

K. Mercy Rosalina is pursuing her Ph.D. in Electrical Engineering from Andhra University, Andhra Pradesh. She obtained her M. Tech in Power Systems from NIE, Mysore. Currently she is associate Professor of EEE, St. Martin's College of Engineering, Hyderabad. Her research interests include distribution system studies, signal processing and AI techniques to power system. 